\title{
REZENSIONEN
}

\section{Markige Merkel-Kritik: pure Polemik?}

\section{Höhler, Gertrud: Die Patin. Wie Angela Merkel Deutschland umbaut, Verlag Orell Füssli, Zürich}

2012, 295 Seiten, $€ 21,95$.

Gertrud Höhler, die selten ein Blatt vor den Mund nimmt, gehört zu den führenden Intellektuellen Deutschlands. Ihr neuestes Buch ist in die Bestsellerliste vorgestoßen. Darin übt sie mehr scharfe als scharfsinnige Kritik an der Bundeskanzlerin. Deren Überzeugung bestehe darin, keine Überzeugung zu haben.

Die konservative Autorin polemisiert in einer pauschalen Art und Weise derart (der Titel ist Programm), dass sie ihr bedenkenswertes Kernargument, Angela Merkel sei macht-, nicht wertebewusst, selber entkräftet. Der Leser erfährt wenig über die Politik Merkels, etwas über ihre Persönlichkeit und - indirekt - viel über die Autorin, die der Kanzlerin eine „freibeuterische Machtmentalität“ bescheinigt. Höhlers Schilderung der „Präsidentendämmerung“ ist treffend und tendenziös zugleich. In diesem „Drama in drei Akten“ (S. 195) zeigt sie, wie das Präsidentenamt von Merkel als eine Art Manövriermasse verstanden wird. Als Antipode zur Kanzlerin firmiert die Lichtgestalt Joachim Gaucks. Er sei ein Freund der Freiheit, Merkel nicht. Was sie über ihn sagt, trifft ins Schwarze, doch ob Merkel Gauck wegen seiner Freiheitsliebe nicht als Bundespräsidenten präferiert hat? Vielleicht wollte sie ihren Fehler von 2010 (sie setzte auf Wulff statt auf Gauck) bloß nicht zugeben.

Höhlers Kritik am plötzlichen, nicht so recht nachvollziehbaren Atomausstieg nach der Katastrophe von Fukushima ist berechtigt, (die deutschen Kernkraftwerke liegen in keiner Erdbebenzone), aber keineswegs die mitunter gehässige Art und Weise, wie sie diese vorbringt, wenn es etwa heißt: „Wer sich Demokratie nicht mehr leisten kann, um an der Macht zu bleiben, sollte nicht an der Macht bleiben." (S. 211) Die Autorin, die in Schwarz-WeißKategorien denkt und (gute) Sachpolitik gegen (schlechte) Machtpolitik ausspielt, unterstellt Merkel nicht nur machtpolitischen Opportunismus, sondern auch die Außerkraftsetzung parlamentarischer Prinzipien. „Deutschland lässt sich ohne Widerstände autoritär regieren, das beweist die ,Energiewende“ bestürzend deutlich.“ In einer Überschrift ist provozierend sogar von einem „Staatsstreich als Chefsache“(S. 261) die Rede.

Höhler, die ihrem Buch die folgende - verräterische - Widmung vorangestellt hat: „Für alle, die die Faust noch in der Tasche haben“ (S. 5), rechnet mit dem „System M“ ab, etwa mit Merkels Behauptung, diese oder jene Entscheidung sei „alternativlos“. Übel sind ihre Ressentiments gegen den Osten („Frau aus Anderland“, S. 71). Sie erklärt das vorsichtige Verhalten der „Newcomerin“ stark mit ihren Prägungen aus der SED-Diktatur. Was unter anderem verstimmt, ist die oft überheblich daherkommende Attitüde („Aufsteigerin im Kostüm des Landeskindes“, S. 35). „System M“ - diese Wendung durchzieht das Werk wie ein roter Faden. Der Rezensent hat das Zählen aufgegeben. Bei den Untertiteln kommt der Terminus immerhin dreimal vor.

Höhler hat mit ihrem - zugegeben - geschliffen geschriebenen Buch den Kritikern Angela Merkels, und es gibt deren viele, einen Bärendienst erwiesen. Doch sollte eine Stilistin und eine Person wie sie, die die Fahne der Freiheit hochzuhalten sucht (die Liberalen gelten als 
gefährlichster Gegner für die Strategie der Kanzlerin), nicht vom „Super-Gau für die Demokratie“ (S. 37) reden: zum einen, weil ein „Gau“ bereits ein Superlativ ist, zum anderen, weil sie auf diese Weise die Grenzen zwischen Demokratie und Diktatur verwischt. Das gilt auch für „Dissidenten“ (S. 177). So heißen im Buch diejenigen, die Merkel Paroli bieten. Höhler behauptet, die Sprache verrate Merkel. Trifft das nicht (ebenso) auf sie zu? Die Macht der Sprache Höhlers ist der Sprache der Macht Merkels offenkundig unterlegen.

Die Frage, ob Angela Merkel in den Fußstapfen Helmut Kohls wandelt, wird nicht angemessen beantwortet. Höhler verweist auf - verhüllte - Kritik Kohls an der Kanzlerin. Aber ist sie mit ihrer Strategie und ihrer Konzeption - dem Machtwillen und der entschiedenen Europapolitik („Scheitert der Euro, dann scheitert Europa“) - nicht die beste „Kohlianerin“? Im Übrigen überschätzt Höhler den Einfluss Merkels massiv, wenn sie den Eindruck erweckt, die Politikerin könne Deutschland mehr oder weniger allein „umbauen“.

Das Werk, für den Tag geschrieben, belegt, wie eine eindrucksvolle Intellektuelle sich von ihren Emotionen mitreißen lässt. Prinzipieller Natur ist die Kritik an der „Allparteien-Koalition“ (S. 213), am „Allparteien-Konsens“ (S. 162) und am „Allparteien-Staat“ (S. 238). Diese Hinweise verdienen eine politikwissenschaftliche Reflexion. Treffen derartige Begriffe zu? Und wenn ja: Was sind die Gründe für eine solche Entwicklung? Liegt das in erster Linie an der Person von Angela Merkel?

Eckhard Jesse

\section{Parteien nach Bundestagswahlen: verlässliche und kontinuierliche Analysen}

Niedermayer, Oskar (Hrsg.): Die Parteien nach der Bundestagswahl 2009, Wiesbaden 2011, VS
Verlag für Sozialwissenschaften, 357 Seiten, € 39,95.

Zu den wichtigsten Publikationen im Bereich der Wahl- und Parteienforschung zählen sicherlich die Bände, die - unabhängig großer Schnittmengen - von den Arbeitskreisen „Wahlen und politische Einstellungen“ und „Parteienforschung“ der Deutschen Vereinigung für Politische Wissenschaft aus Anlass der Bundestagswahlen erarbeitet werden. Mit ihnen lassen sich die jeweiligen Bestimmungsgründe einer Wahl und das Abschneiden der Parteien kontinuierlich verfolgen. Nicht nur für die „Scientific Community“, sondern gerade auch für die wissenschaftlich orientierte Öffentlichkeit ist besonders die Kontinuität der Analysen von großem Vorteil. Seit 1993 sind allein 14 Bände im Rahmen des Arbeitskreises Parteienforschung erschienen. In denen, die den Bundestagswahlen gewidmet sind, finden sich regelmäßig Analysen zu den einzelnen Bundestagsparteien, der Entwicklung des Parteiensystems sowie eine Anzahl von variierenden Einzelaspekten. Nach dem schlechtesten Abschneiden der Volksparteien seit 1949 bei der Bundestagswahl 2009, ist es naheliegend, dass die Ursachen für diese Veränderungen das Schwerpunktthema des vorliegenden Buches bilden.

Der Sprecher des Arbeitskreises Parteienforschung und Herausgeber des Bandes, Oskar Niedermayer, ist einer der Garanten dieser Kontinuität, da er zuverlässig die Entwicklungen des Parteiensystems nach festen systematischen Kategorien vermisst. Trotz des Wandels zu einem „pluralistischen“ (S. 7) und „fluiden“ (S. 34) Fünf-Parteien-System schlussfolgert er keinesfalls - gegen einen weit verbreiteten Trend - dass das „Ende der Volksparteien“ ein- 